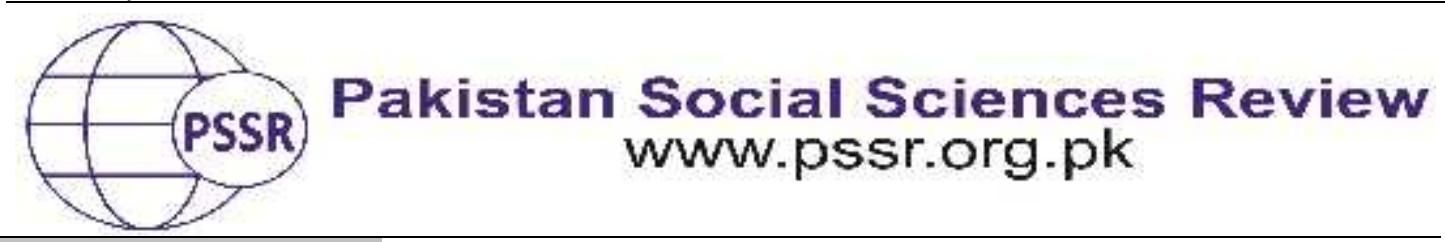

\title{
RESEARCH PAPER \\ Assessing Effect of Listening English Text based Audios by Native Speakers on Reading Fluency of Intermediate Students
}

\author{
Mumtaz Naeem ${ }^{* 1}$ Dr. Sajid-ur-Rehman ${ }^{2}$
}

1. Ph. D Scholar, Department of Education, Northern University, Nowshera, KP, Pakistan

2. Assistant Professor, Department of Education, Northern University, Nowshera, KP, Pakistan

\begin{tabular}{l}
\hline PAPER INFO \\
\hline Received: \\
March 04, 2021 \\
Accepted: \\
May 01, 2021 \\
Online: \\
May 15, 2021 \\
\hline Keywords: \\
Listening English \\
Text-Based Audios, \\
Native Speakers, \\
Reading Fluency, \\
True Experimental \\
Design \\
\hline *Corresponding
\end{tabular}

*Corresponding

Author

mumtaznaeem50

@gmail.com

\section{ABSTRACT}

This study tried to assess the effect of listening English textbased audios by native speaker on reading fluency of intermediate students. A sample of 60 mixed ability learners was selected from grade XI of Government Boys Higher Secondary School, Kamra and divided them into two equal groups i.e., Control group $(n=30)$ and experimental group $(n=30)$. At that time the reading fluency pre-test was managed to assess contestants' listening comprehension from the start of course. The experimental group (EG) was taught by audios by native speakers. The control group (CG) was taught by audios Compact Disk (CD) developed by three assistants of the researcher as the teaching aid. The researcher chose the Pretest-Posttest equivalent group design which was the sub-type of true experimental design. The researcher managed the post-test after four weeks' treatment to find out the effect of English text-based audios by native speakers and audios Compact Disk (CD) on teaching reading fluency. The collected data was analyzed by the use of independent and paired samples t-tests. The results revealed that the mean score of post-tests of experimental group was higher than the control group. Moreover, the t-test of experimental group was higher than that of control group. Consequently, the null hypothesis was rejected. The alternative hypothesis was accepted. It is, therefore, recommended that all students should be provided learning technique of listening English text-based audios by native speakers to increase reading fluency of students.

\section{Introduction}

Reading is the skill that is acquired through listening skills (Harris and Hodges, 2004). Reading is generally distributed into two parts: (a) automated movement which contains reading the marks (words, sentences, paragraphs) placing on the side and interpreting. During this process, the mind gets signals from the eye. 
There is an essentially a copy assignment on this automated point; (b) at hand is reception chore that is for understanding the descriptive clarification, during which a learner obtains to understand for logic and the justification of the author.

The preliminary achievement requires visual assistance assessment. The second is mostly concerned with the skills of the student. Therefore, it can be concluded that reading is concerned with the process of automatic expertise of identification, classifying the significance of vocabulary, incorporating semantic and structural points, and linking this to their reader's own extensive information and the intellectual capacity of the area that is under discussion and being understood".

Harrison (2015) stated that reading comprehension is a versatile evolution that occupies building denotation, adding knowledge and assembling presupposition. As stated by Ryburn (2013) the pupil is familiarized to the five diverse types of reading for this purpose: a) Skimming is very useful in the wide-ranging reading. It is a technique used to get the substance of the topic material. The plan of first reading is to get the main idea of the text. In general, the primary sentence upholds the main thought of the text. In other words, skimming is to find out the main topic. b) Scanning is a method that is unlike skimming. It involves looking for thorough information in the text. This is that information that the reader has read lately. One checks the sheets of a dictionary to search a precise word. One looks into the directory of a dimensions looking for a difficult object. Hence, scanning helps the reader to find out and assist the students search rapidly for the precise information that is mandatory by a pupil.c) Comprehensive Reading: a student must read cautiously for familiarity of a text in order to dig up information and understand the text.d) Critical Reading: the finest reading is the critical reading that enables the reader to be aware of the authors' rationale, to discriminate between facts and illustrate inferences from what is accessible. e) SQ 3R Formula: SQ3R is a useful method that the teacher can usefully utilize while dealing with bigger texts. The $S$ in SQ3R formula means 'Survey'. The $Q$ is for 'Questions'. And the 3Rs stand for 'Reading', 'Review and 'Recite'.

Reading Fluency is concerned with reading a document swiftly and with the right expression (National Reading Panel, 2006). Fluency is the potential of reading straight forwardly and without complexity at an unsurpassed speed with first-class wording. Fluent reading should be like talking precisely, fluently and quickly. (Bellinger and Diperna, 2011).Fluency refers to reading words accurately with good tempo. It is also related to inserting in one's accent and basics of expression along with the wording. It also engages the softness that is the ability to understand straightforwardly and smoothly at a good speed with better choice of words and phrases that builds up more than time as learner's words classification aptitude gets better. According to Rasinski(2004) Reading fluency is an essential component in becoming a proficient booklover. Torgesen (2006) classified that the workings of fluency can be continually tested with accuracy and rate. A small fluency assessment is solicitous of a brawny view of fluency with a focus on rate and accuracy except for 
a deeper view of fluency that inculcates other features such as perception. (Denney, 2010). Stahl et. al (2003) stated that the training of many types of reading fluency set up students for reading speed. The researcher suggests that there are three kinds of drills which are used to build up students reading speed; speed with wide perception, curriculum's evaluation and regular understanding.

Choice of words betters over time as students' speech recognition skill picks up. Students, who are little of fluency, study step by step. They take break linking expressions and vocabulary and usually make repeated mistakes. They do not repay consideration to punctuation marks and understand in a mono pitch (Grabe, 2010). It is the responsibility of a teacher to educate the students to be pleased about what he understands and put together with what he previously makes out.

Reading speed refers to the student's capacity to distinguish words rapidly. Reading rate further passes on to the pupil's skill to recognize words speedily. Reading speed improves by reading a lot (Breznitz, 2006). According to Cook (2010) fluent booklovers are well-known with the language skill and so have no trouble in starting conversations and using their observant vitality in structural sense. The speed in which a text is read is called reading rate. Reading rate includes trouble-free acknowledgment of student's vocabulary as well as the speed. It also includes smoothness with which a booklover moves about related texts. It involves automaticity that is quick and exact word approval that guides to self-assurance. (Rasinski, 2000).

Perfetti (1999) stated that systematic vocabulary of students can be improved by vocabulary building. This can be done by including phonological rules which help to articulate the technique in which word categorization happens.

The main components of reading fluency are word recognition and decoding skills. As stated by Grabe (2010) reading fluency consists of four elements: Automaticity, precision, evaluation speed and prosodic arrangement. Automaticity passes on the skill of the pupil to extend the text-book missing the use of exterior possession rapidly. Accuracy passes on to the exact handing out of vocabulary in a record. Prosodic structuring means that when fluent readers read the words speedily and correctly, they get the essence of a language.

According to the National Institute of Child Health and Human Development (2000) reading fluency is a noteworthy trait of skillful interpretation. There are most important investigators in the territory of L2, who compel the consequence of cultivating reading fluency to pupils. Prosodic features have differences in period (span of time) and pitch (rise and fall of sound), pressure model (syllabic upper hand), and that adds to communicative understanding of a book. These elements are astonishment, sign inquiry and shout. These are all prosodic aspects which widen reading fluency (Kuhn et al. 2010) Prosody are a languagebased term that explains the musical and tonal aspects of language: the melody of spoken verbal communication (Dowhower, 1991). 
Skill development is considered to be an important part of educational system since 2000. Skill development is center of individual performance and learning in educational institutions. There are many research studies which found association among learning effect and study skills' approaches. The diverse studies were conducted on listening skills in order to extend listening comprehension, listening fluency and repeated reading in college student. (Cottrell, 2001)

Chang, A. C., \& Millett, S (2014) studied the consequence of broad listening on increasing L2 listening and reading fluency. He used three groups of L2 students. The study examined the outcome of developing L2 listening and reading fluency to audio graded readers through extensive listening. This study used a huge store of listening fluency development questions (2064 items) which were made for $10^{\text {th }}$ grade readers. The sample of this study consisted of 113 low intermediate EFL university students. All participants were students of English proficiency courses. The participants were made into three groups according to the pre-test scores by the researcher. This study was experimental in nature. The outcomes of the presented study revealed that listening is the most proficient approach in improving L2 listening and reading fluency. The results of the present study propose that plentiful input and trustworthy practices are crucial to improve listening and reading fluency. Researchers such as Chen (2003) stated that reading fluency is associated to students' spoken capacity. There were three groups of L2 students who were available over a thirteen weeks' period. The treatment for the sampled group was listening, reading and reading while listening and. All sampled students were pre-tested in 60 items before the association and one post-test was taken of three texts (180 items) after the involvement. The texts of this study were read at the same speech rate, whereas the participants were allowed to listen only one time. The post test results discovered that listening plus reading produced the most invariable and significant outcomes. The results have some suggestions for increasing L2 listening and reading fluency.

Brown (2006) did study on foreign language learning. His studies have confirmed that coordinated listening and reading should be preferable because these made their input more comprehensible.More recently, Chang (2011) worked with 7 ESL learners who all mutually read and listened to $28 / 39$ audio graded readers (delivered at 160 words per minute) over 26 weeks' period. She found that participants improved significantly not only their wide-ranging vocabulary but also their listening fluency while participants who did not receive the behavior, they did not recover their general vocabulary, listening and reading fluency. However, Chang (2012) studied 34 ESL university students who also alongside read and listened to 13 audio graded readers over 26 weeks. There was a minor effect on their listening performance.

Taugchi (1997) studied the effects of RR on the oral English and silent reading rate of 15 Japanese college students from start to intermediate levels. They met three times each week over 10 weeks' period. The results stated that their silent reading rates increased significantly their oral skills. Chen (2003) did an experimental study 
on reading fluency. He recommended the vital part of Repeated Reading (RR) which was speed. This part was also stressed on by Kuhn (2004). It was recommended that the most important focus of Repeated Reading (RR) was the procedure that led to an improved "speed". Repeated Reading (RR) cannot only increase learners reading skill but also helped them with their speaking capability. In other studies, Kuhn and Stahl (2003) recommended that Repeated Reading could provide as an enlightening practice for fluency training. Fuchs (2001) and colleagues have recognized that reading fluency links with ordinary reading comprehension measures at very high levels (Fuchs et al., 2001\& Jenkins et al, 2001). For example, Fuchs et al. (2001) established that reading fluency was greatly linked to the reading perception.

"CBM" (Curriculum Based Measurement) presented a good indicator of reading skill, including understanding." (Shinn et al., 1992). The research passed on by Pilonieta (2012) corresponds with Denney (2010) that collectively states that fluency is further than speed and correctness.

"It is a constructive approach to listen to stories for language listening and reading ability for kids who are in threat for reading to go down." (Brown, 2006). Listening While Reading (LWR) is one of three ways that results from the Neurological Impress Method (NIM). NIM promotes softness by letting students and educators to read persuasively in a choral group.Therrien (2004) stated that Listening While Reading (LWR) is a tactic that holds up the main idea of Neurological Impress Method (NIM)by cheering students to read beside with an individual or audio of an orator. Hudson, Lane \& Pullen (2005)stated that "students make use of reasonably much of their sense of humor as being attentive towards recorded books: paying attention to looking at images, hearing, and following along with a touch (concrete)". Pupils who are universal learners with a good sense and have grasp on the comprehensive trends are the ones who get the most advantage from English text-based videos by the native speakers of the language on listening comprehension. Hudson, Lane and Pullen (2005) initiated that English text-based videos by native speakers enhanced reading skills,expressions and grasp on the language. Reading skills were not explained in requisites of definite fluency skills. This is well-known through an array of studies that there is a broad connection amid general reading achievement and reading fluency.

One Minute effectiveness and measurement help a teacher to know about the students who are not able to read precisely or quickly. These students are not provided with the proper information which is required for being able to read hastily, and that is the reason of not being able to read with accuracy or speed (Denney, 2010). One-minute effectiveness and measurement help in providing learning in the classroom. Teaching is a reply to get an enhanced examination, effortlessness and additional literacy skills

Listening to audios by the native speakers of a language is more efficient in escalating reading rate. (Kuhn, 2010). Giving students the chance to preview a reading passage will amplify their reading pace when they read the text clearly. Both 
previewing by Listening While Reading (LWR) and quiet previewing will boost reading rate significantly.

In a similar research, Chang (2012) stated that the most important gains in accurateness were results of listening to audios or listening audios by native speakers of a text or discussion.Rost (1994) indicated that listening helps in developing listening and reading comprehension. That is why, listening comprehension augments reading fluency. The recent study results match with the consequences of Rost (1994), which clearly indicates that listening by native speakers improves listening comprehension. It complies that listening English text-based Audios play an innermost job in the prime and progress of Listening capacity and reading fluency.

Chao (2010) did a research on reading fluency. The consequences of the learning states that Listening is needed to develop fluency in reading. Fluent reading develops a logic of achievement and self-assurance in readers. Since fluency is a significant component in reading, it is noteworthy to give charge to its expansion. The results of the study were that our most important ambition in our literary lessons should be listening comprehension and reading fluency with comprehension.

\section{Hypotheses of the Study}

Ho1: There is no important distinction amid the average marks of pre-test and post-test of control group and experimental group on reading speed/ rate test.

Ho2: There is no important distinction amid the average marks of pre-test and post-test of control group and experimental group on reading accuracy test.

Ho3: There is no important distinction amid the average marks of pre-test and post-test of control group and experimental group on reading prosody scale.

\section{Material and Methods}

This research was experimental in nature. The researcher selected the Pre-test Post-test Equivalent Group Design for this study. This study aimed at to examine the effect of listening English text-based audios by native speakers on listening comprehension and reading fluency of Intermediate students.

The population of this study was 718,819 students who were studying in government higher secondary schools in Punjab. These schools are being controlled and monitored by Department of Education, Government of the Punjab, (EMIS 20172018). 
The sample of this research was 60 mixed ability students of first year class from Government Boys Higher Secondary School, Kamra, Attock. They were selected by simple random sampling procedure. Their academic performance was considered in English language in secondary school class examinations of Board of Intermediate and Secondary Examination, Rawalpindi during their selection.

\section{Research Instruments}

The research tools of this research were Listening Dialogues of Intermediate class which were selected from a website www.talkenglish.com and Objective Type Questions of Listening Comprehension. The research tools used in this study were Pre-test and post-test. These tests were based on Intermediate English listening dialogues based on a website called www.talkenglish.com.

\section{Research Design}

The design of this research was "The Pre-test Post-test Equivalent Group Design". According to Farooq, "This design is a sub-type of True-experimental Design(2017, 128).The investigator used Pre-test Post-test Equivalent Group Design. This design has been practiced in this kind of experimental research as cited by Best, Kahn $(1986,127)$.

\section{Procedure of treatment}

The following procedure was used to conduct the study:

\section{Reading Fluency Test (RFT)}

The researcher used Pre-test as a technique to measure students' reading ability. The students got an opportunity to listen to dialogues at website www.talkenglish.com. In the first step, the students listened to the audio files of the dialogues. This step improved their English listening skills. The students had to pay attention to auditory files of dialogues. Their reading fluency test was taken according to a Multi-Dimensional Fluency Scale developed by Hosp, Hosp and Howell. (2007).

\section{Treatment}

The researcher employed Pretest-Posttest equivalent group design. This design was a sub-type of true-experimental design. The procedure adopted in this design was that one group was presented pre-test. Later on, this group was further split into two sub-groups haphazardly. The procedure adopted was the selection of both groups that had almost equal average score on pre-test. The tested pupils were separated into two groups by making control group and experimental group. Each group had thirty (30) students. The researcher gave four weeks treatment in reading fluency to experimental group but no treatment was given to control group. They were taught by audios Compact Disk (CD) developed by three assistants of the 
researcher as teaching aids. These assistants also used dialogues of website www.talkenglish.comto teach experimental group by providing an opportunity to students to listen English text-based audios by native speakers on listening comprehension.

\section{Selection of the Content}

There were twenty-five listening dialogues for intermediate students. These dialogues were selected from the website www.talkenglish.com. The students got an opportunity to listen to dialogues at website www.talkenglish.com. In the first step, the students listened to the audio file of first dialogue. This step improved their English listening skills. The students were directed to listen to auditory file of the first dialogue in the beginning. The pilot-testing of pre-test and post-test of reading fluency was also conducted on 10 students which was found to be reliable.

\section{Training in Boosting Reading Fluency}

The researcher gave training to three assistants for three days who were the English teachers. The motive of this training was to make students of experimental group to be acquainted with technique of reading dialogues and use these dialogues for increasing reading fluency. Moreover, on the first day, the students were made familiar with the website www.talkenglish.com.

The students were directed to open this website and click the intermediate listening dialogue. On the $2^{\text {nd }}$ Day, the students were directed to listen the dialogues one by one. On the $3^{\text {rd }}$. day, the students were taught how they would listen the dialogues one by one and how their test will be taken according toa MultiDimensional Fluency Scale developed by Hosp, Hosp and Howell. (2007).

\section{Duration of the Treatment}

The whole period of this treatment was four weeks. The researcher started the treatment for reading fluency on $15^{\text {th }}$ October, 2020 and this continued up to 12thNovember, 2020. There were classes of treatment for 6 days in a week from Monday to Saturday. The interval of one period was 40 minutes. The interval of total treatment period was 24 days in a month for reading fluency.

\section{Procedure of Treatment}

The researcher arranged a specific period to conduct the study in the computer laboratory with the permission of the Principal of the concerned institution. The students of experimental group were taken to the computer laboratory in $4^{\text {th }}$ period. These sample students were divided into six groups. Each group had five students. These selected students of experimental group were given directions before the start of the experiment on listening of dialogues on computer. 
When these students had finished the first dialogue, their test was taken according to the scale developed by Hosp, Hosp and Howell (2007). The score of each student was noted down in a concerned book of each student in a table of that concerned note-book. A video was made for each period of the day for the sake of maintaining the record. A monitor was appointed in each group to note down the score of every member of a group in a table of a note-book. Besides, the video of each student's score was made in order to note down the scores of each student. The record of each student was made in that concerned note-book by assistants of the researcher who were given the training before the start of experiment. In addition to, the traditional procedure for developing the reading fluency was adopted by the assistants of the researcher in the conduct of the study of control group.

The three sub-skills of reading fluency are speed, accuracy and prosody. Hosp, Hosp and Howell (2007) developed a Curriculum-Based Measurement Reading Fluency Scale. Rasinski (2004) developed a multi-dimensional fluency scale. The researcher used this scale to measure reading prosody before the start of experiment and at the end of experiment on each day.

During experiment, the students were directed how to develop Pitch, spell, stress, and pausing while teaching through dialogues. These were all prosodic features that were given special emphasis to develop reading fluency. The students were also directed how to develop suitable prosody through their consideration of the background of the text and by using text cues. Correct expressions, rise and fall of speech and strain among sampled students were also developed through reading practice of dialogues. Reading Fluency of sample students was checked through automaticity, correctness, reading pace and prosodic formation of the selected text.

The researcher developed an observation checklist to assess sampled students' attention and involvement of students. This observation list aimed at finding out effect of listening English text-based Audios by native speakers on reading fluency of Intermediate students. Three points scale was developed in the form of low, moderate and high. Through this scale, students' degree of level of attention and involvement was assessed on daily basis.

Data was collected with the help of three assistants and an Independent t-test was used. The pre-test and post-test of reading speed was analyzed. Further, the researcher also analyzed pre-test and post-test of Reading Accuracy. He also analyzed pre-test and post-test data of Reading Prosody. The researcher further interpreted this data at 0.05 significant levels. Data concerning students' levels of attention and involvement was obtained through checklist.

Reading Fluency of dialogues was assessed through speed/rate, accuracy, efficiency and prosody. The Reading Fluency was assessed by using the scale i.e., CBM-ORF Scale (Curriculum-Based Reading Fluency Scale) developed by Hosp, Hosp and Howell in 2007. Rasinski's Multi-Dimensional Fluency Scale was used to measure reading prosody in the beginning of the treatment and at the end of 
treatment. Reading Fluency was measured through three componential elements: reading rate/speed, reading accuracy and reading prosody at 0.05 levels of significance. Data was collected and analyzed by descriptive and inferential statistics.

\section{Reading Speed}

\section{Hypothesis 1 tested}

Ho1: There is no important distinction amid the average marks of post-tests of control group and experimental group on reading speed/ rate test.

Table 1

Important dissimilarity between the average counts of Control Group and Experimental Group on post-tests concerning fluency's sub-scale Reading

\section{Speed/Rate}

\begin{tabular}{cccccc}
\hline Group & N & Mean & SD & t-value & p-value \\
\hline Post-test & 30 & 167.96 & 46.01 & \multirow{2}{*}{2.580} & 0.118 \\
\hline Post-test & 30 & 190.50 & 52.18 & & \\
\hline Significance level $=0.05$ & $\mathrm{df}=58$ & \multicolumn{2}{c}{ Table value at 0.05 level $=2.00$}
\end{tabular}

Table 1 shows the result of control group and experimental group on posttest. The mean value of post-test of control group was 167.96. The mean value of post-test of experimental group was 190.50. The comparative analysis of mean value of control group and experimental group indicates that mean value of reading speed test of experimental group post-test was 190.50 and control group is 167.96 which was greater than post-test value of control group. It was further confirmed by $\mathrm{p}$ value which was greater than 0.05 (P-0.118>0.05).

The null hypothesis was rejected and alternate hypothesis was accepted on the basis of comparative analysis of mean values of both groups. This proves that listening English text-based audios by native speakers' increases reading speed of experimental group.

\section{Reading Accuracy}

\subsection{Hypothesis 2 tested}

Ho2: There is no important distinction amid the average marks of post-test of Control Group and Experimental Group on Reading Accuracy test.

Table 2

Important dissimilarity between the average counts of Control Group on posttests concerning Reading Accuracy Test

\begin{tabular}{cccccc}
\hline Group & N & Mean & SD & t-value & p-value \\
\cline { 1 - 3 } Post-test & 30 & 96.021 & 1.598 & \multirow{2}{*}{6.108} & \multirow{2}{*}{0.000} \\
\hline Post-test & 30 & 99.430 & 0.763 & & \\
\hline
\end{tabular}


Significance level $=0.05 \quad \mathrm{df}=58 \quad$ Table value at 0.05 level $=2.00$

Table 2 shows the result of control group and experimental group on posttests. The mean value of post-test of control group was 96.021. The mean value of post-test of experimental group was 99.430 . The comparative analysis of mean value of control group and experimental group indicates that mean value of reading accuracy test of experimental group's post-test was 99.430 and control group was 99.021 which was greater than post-test of control group. It was further confirmed by $\mathrm{p}$-value which was smaller than $0.05(\mathrm{P}-0.000<0.05)$.

The null hypothesis was rejected and alternate hypothesis was accepted on the basis of comparative analysis of mean values of both groups. This proves that listening English text-based audios by native speakers' increases reading accuracy of experimental group.

\section{Reading Prosody}

\subsection{Hypothesis 3 tested}

$\mathrm{Ho}_{3}$ : There is no important distinction amid the average marks of pre-test and post-test of control and experimental group on reading Prosody Scale.

Table 3

Important dissimilarity between the average counts of Control Group and Experimental Group on post-tests concerning Reading Prosody Scale

\begin{tabular}{cccccc}
\hline Group & $\mathbf{N}$ & Mean & SD & t-value & p-value \\
\cline { 1 - 4 } Post-test & 30 & 13.90 & 2.090 & \multirow{2}{*}{11.834} & 0.000 \\
\cline { 1 - 5 } Post-test & 30 & 14.63 & 1.245 & & \\
\hline Significance level $=0.05$ & $\mathrm{df}=58$ & \multicolumn{2}{c}{ Table value at 0.05 level $=2.00$}
\end{tabular}

Table 3 shows the result of control group and experimental group on posttests. The mean value of post-test of control group was 13.90. The mean value of post-test of experimental group was 14.63. The comparative analysis mean value of control group and experimental group indicates that mean value of reading prosody test of experimental group post-test is 14.63 and control group is 13.90 which was greater than post-test of control group.

The null hypothesis was rejected and alternate hypothesis was accepted on the basis of comparative analysis of mean values of both groups. This proves that listening English text-based audios by native speakers' increases reading prosody of experimental group.

\section{Discussion}

The sub-skills of reading fluency are reading speed, reading accuracy and reading prosody. The results of the study indicate that the strategy of listening 
English text-based audios by native speakers improved reading speed, reading accuracy and reading prosody of experimental group significantly as compared to control group.

Likewise, the researcher examined the achievement of control group and experimental group in terms of post-test of reading speed. The comparative analysis of mean score of control group and experimental group indicated that the mean score of post-tests of experimental group in reading speed was greater than the mean score of post-tests of control group. On the basis of results, the null hypothesis (Ho1) was rejected. It means that the strategy of listening English text-based Audios by native speakers' improved reading speed of experimental group significantly.

Likewise, the researcher examined the achievement of control group and experimental group in terms of post-test of reading accuracy. The comparative analysis of mean score of control group and experimental group indicated that the mean score of post-test of experimental group in reading accuracy was greater than the mean score of post-test of control group. On the basis of results, the null hypothesis (Ho2) was rejected. It means that the strategy of listening English textbased audios by native speakers' improved reading accuracy of experimental group significantly.

In the same way, the researcher examined the achievement of control group and experimental group in terms of post-test of reading prosody. The comparative analysis of mean score of control group and experimental group indicated that the mean score of post-test of experimental group on reading prosody was greater than the mean score of post-test of control group. On the basis of results, the null hypothesis (Ho3) was rejected. It means that the strategy of listening English textbased Audios by native speakers' improved reading prosody of experimental group significantly.

\section{Conclusions}

The study proved that the three sub-skills like reading speed, reading accuracy and reading prosody of Reading Fluency (RF) of students of Experimental group have increased with the help of listening English text-based Audios by native speakers. It means that using a strategy of listening English text-based Audios by native speakers improved the Reading Fluency (RF) of students of experimental group

1. The performance of experimental group on reading speed on post-test score was much better than post-test score of control group. The results indicated that the mean score of reading speed of experimental group in post-test was much better than the mean score of control group in post-test. It proved that listening English text-based Audios by native speakers increased the reading speed of experimental group. 
2. The performance of experimental group on reading accuracy speed on Posttest score was much better than post-test score of control group. The results indicated that the mean score of reading accuracy of experimental group in post-test was much better than the mean score of control group in post-test. It proved that listening English text-based Audios by native speakers increased the reading accuracy of experimental group.

3. The performance of experimental group on reading prosody scale on posttest score was much better than post-test score of control group. The results indicated that the mean score of reading prosody scale of experimental group in post-test was much better than the mean score of control group in posttest. It proved that listening English text-based Audios by native speakers increased the reading prosody scale of experimental group.

\section{Recommendations}

1. The study revealed that the performance of experimental group on reading speed on post-test score was much better than post-test score of control group. It is, therefore, recommended that all students should be provided learning technique of listening English text-based Audios by native speakers to increase reading speed of students.

2. The study revealed that the performance of experimental group on reading accuracy on post-test score was much better than post-test score of control group. It is, therefore, recommended that all students should be provided learning technique of listening English text-based Audios by native speakers to increase reading accuracy of students.

3. The study revealed that the performance of experimental group on reading prosody scale on post-test score was much better than post-test score of control group. It is, therefore, recommended that all students should be provided learning technique of listening English text-based Audios by native speakers to increase reading prosody scale of students. 


\section{References}

Bellinger, J. M., \&DiPerna, J. C. (2011). Is fluency-based story retell a good indicator of reading comprehension? Psychology in the Schools, 48(4), 416-426

Bergeron, S. (2001). Review and Assessment of Technology and Materials for English Language Teaching and Learning. Listening Dialogues for Intermediate Students. website: www.talkenglish.com.

Breznitz, Z. (2006). Fluency in reading: Synchronization of processing. Mahwah, NJ: L. https:/ / eyebooks.demicon.ru/download.php?id=198

Brown, S. (2006). Teaching listening. New York: Cambridge University Press.

Chang, A. C., \& Millett, S. (2014). The effect of extensive listening on developing L2 listening fluency: Some hard evidence. ELT journal, 68(1), 31-40.

Chang, C. S. (2012). 'Gains to L2 learners from extensive listening: listening development, vocabulary acquisition and perceptions of the intervention'. Hong Kong Journal of Applied linguisticsI4/ I: 25-47.

Chao, J.Y. (2010). The influence of Strategy's use on comprehension and recall of authentic listening text by Chinese EFL students in Taiwan. (Doctoral dissertation) university of Minnesota.

Cook, V. (2010). Second Language Learning and Language Teaching. New York: Oxford University Press.

Cottrell, S. (2001). Teaching Study Skills and Supporting Learners. New York: Palgrave Macmillan

Denney, T. A. (2010). One-minute fluency measures: Mixed messages in assessment and instruction.TheReading Teacher, 63(6), 440-450.

Farooq, R. A. \& Tabassum, R. (2017). Understanding Research in Education. Institute of Education and Research, University of Arid Agriculture, Rawalpindi.

Fuchs, L. S., Fuchs, D., Hosp, M. K. \& Jenkins, J. R. (2001). Oral Reading Fluency as an Indicator of Reading Competence: A Theoretical, Empirical and Historical Analysis. Scientific Studies of Reading.5 (3), 239-256.

Grabe, W. (2010). Fluency in Reading - Thirty-Five Years Later. Reading in a Foreign Language, New York: Cambridge University Press.

Government of Punjab, (EMIS 2017-18). Annual statistical Report of Government Schools: Elementary and Secondary Education Department, Provincial Directorate of Education. 
Harris, T. L., \& Hodges, R.E. (2004). The literacy dictionary, the vocabulary of Reading and writing. New York, DE: International Reading association.

Harrison, M. L. (2015). Reading Readiness. Reading in a Foreign Language, New York: Guilford Press.

Hosp, M. K., Hosp, J. L. \& Howell, K.W. (2007). The ABC's of CBM: A Practical Guide to Curriculum Based Measurement. New York: Guilford Press.

Hudson, R. F., Lane, H.B., \& Pullen, P.C. (2005). Reading fluency assessment and instruction: What? Why? and How? The Reading Teacher, 58 (8).

Kuhn, M., Schwanenflugel, P, J., E.\&Meisinger, E. B. (2010).Aligning Theory and Assessment of reading fluency: automaticity, Prosody and Definition of fluency,Reading Research Quarterly; 45, 230-251.

Kuhn, M. R., \& Stahl, S. A. (2003). Fluency: A review of developmental and remedial practices. Journal of educational psychology, 95(1), 3.

Kuhn, M. (2004). Helping students become accurate, expressive readers: Fluency instruction for small groups. The Reading Teacher, 58(4), 338-344.

National Reading Panel, (2006). Report of the National Reading Panel:Teaching Children to read: An Evidence-based Assessment of the Scientific Research Literature on Reading and its Implications for Reading Instruction. (NH Publication No. 00-4769) National Institute of Child Health and Human Development, and Department of Education, Washington, DC: US Department of Health and Human Services.

Perfetti, C. A. (1999). Comprehending written language: A blueprint of the reader. The neurocognition of language, 167, 208. New York: Oxford University Press.

Rasinski, T.V. (2004). Creating Fluent Reader: Educational Leadership. Reading Research Quarterly, 37, 410-422. doi/10.1598/RRQ.30.4.5

Rost, M. (1994). Introducing listening. Penguin. London: Penguin books.

Taguchi, E. (1997). The effect of Repeated Reading on the Development of Lower Identification Skills of FL readers. Reading in a Foreign Language', 11, 97-119. 